Journal of Southeast Asian

\title{
Acculturative and Psychosocial Predictors of Academic-Related Outcomes among Cambodian American High School Students
}

\author{
Khanh Dinh \\ University of Massachusetts Lowell, khanh_dinh@uml.edu \\ Traci L. Weinstein \\ University of Illinois at Chicago, tweins2@uic.edu \\ Su Yeoung Kim \\ University of Texas at Austin, sykim@prc.utexas.edu \\ Ivy K. Ho \\ University of Massachusetts Lowell
}

Follow this and additional works at: https://docs.lib.purdue.edu/jsaaea

Part of the Asian American Studies Commons, Bilingual, Multilingual, and Multicultural Education Commons, and the Race and Ethnicity Commons

\section{Recommended Citation}

Dinh, Khanh; Weinstein, Traci L.; Kim, Su Yeoung; and Ho, Ivy K. (2008) "Acculturative and Psychosocial Predictors of Academic-Related Outcomes among Cambodian American High School Students," Journal of Southeast Asian American Education and Advancement: Vol. 3 : Iss. 1, Article 6.

DOI: $10.7771 / 2153-8999.1102$

Available at: https://docs.lib.purdue.edu/jsaaea/vol3/iss1/6

This document has been made available through Purdue e-Pubs, a service of the Purdue University Libraries. Please contact epubs@purdue.edu for additional information.

This is an Open Access journal. This means that it uses a funding model that does not charge readers or their institutions for access. Readers may freely read, download, copy, distribute, print, search, or link to the full texts of articles. This journal is covered under the CC BY-NC-ND license. 


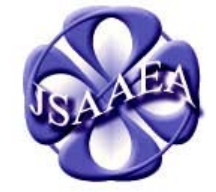

Volume 3

\section{Journal of Southeast Asian American \\ Education \& Advancement}

WWw.JSAAEA.org
A peer-reviewed

scholarly journal

published by the

National Association

for the Education \&

Advancement of

Cambodian, Laotian, and Vietnamese

Americans (NAFEA)

\title{
Acculturative and Psychological Predictors of Academic-Related Outcomes Among Cambodian American High School Students
}

\author{
Khanh T. Dinh \\ University of Massachusetts Lowell \\ Traci L. Weinstein \\ University of Illinois at Chicago \\ Su Yeong Kim \\ University of Texas at Austin \\ Ivy K. Ho \\ University of Massachusetts Lowell
}

\begin{abstract}
This study examined the acculturative and psychosocial predictors of academicrelated outcomes among Cambodian American high school students from an urban school district in the state of Massachusetts. Student participants $(N=163)$ completed an anonymous survey that assessed demographic characteristics, acculturative experiences, intergenerational conflict, depression, and academicrelated outcomes. The main results indicated that acculturative and psychosocial variables were significant predictors of academic-related outcomes. Specifically, students' Cambodian cultural orientation was positively associated with their beliefs about the utility of education and sense of school membership, while students' Anglo/White cultural orientation was positively associated with their grade point average, educational aspirations, and sense of school membership. Results also indicated that Cambodian cultural orientation was negatively associated with intergenerational conflict, which in turn was associated with depression. This study provides important information to developers of schoolbased and family-based prevention and intervention programs by highlighting the acculturative challenges and how academic success can be fostered for Cambodian American students.
\end{abstract}

\footnotetext{
@

SOMERIGHISRESEREDRReaders are free to copy, display, and distribute this article, as long as the work is attributed to the author(s) and the Journal of Southeast Asian American Education \& Advancement, it is distributed for noncommercial purposes only, and no alteration or transformation is made in the work. More details of this Creative Commons license are available at http://creativecommons.org/licenses/by-nc-nd/3.0/. All other uses must be approved by the author(s) or JSAAEA.
} 
Key words: Cambodian, high school students, acculturation, intergenerational conflict, depression, academic outcomes.

Cambodia has experienced a turbulent history over the past thirty years, resulting in the traumatic relocation of more than 150,000 Cambodian people to the United States (Chan, 2004). Relocated after the obliteration of their culture, society, and educational structure, Cambodian refugees in America have had to adjust to a culture, society and educational system that is very different from their own. In Massachusetts, the Southeast Asian population, of which Cambodians are the second largest group, has increased nearly $200 \%$ in the last decade (Lotspeich, Fix, Perez-Lopez, \& Ost, 2003). In one particular urban school district, thirty-three percent of students enrolled are of Asian descent and most of this population is Cambodian (Massachusetts Department of Education, 2004). Cambodian adolescents are especially at high risk for dropping out of high school (Wright, 1998). Because educational success is one of the main indicators of individual well-being (Hammond, 2004; Mok, 2006), there is a great need to examine specific factors that can impact the academic achievement of Cambodian American students.

\section{Historical Context}

The recent history of Cambodia has been characterized by violence, chaos, and trauma (Chan, 2004; Sharp, 2003). In 1975, the Khmer Rouge regime took control in Cambodia. The purpose of this government was to create a communist-socialist society of agrarian peasants. To this end, mass murders were committed against those who were viewed as possible enemies of the new state, including academics, merchants, public officials, religious leaders, and anyone who was deemed to be nonconformist. During their rule, the Khmer Rouge murdered more than one-fifth of Cambodia's population, and life for the survivors was characterized by forced relocation to labor camps, starvation, and torture. Escape from Cambodia was horrific, often involving dangerous journeys through jungles and land mines (Sharp, 2003). Refugees who did not perish during the flight relocated to refugee camps in Thailand. Subsequently, more than 300,000 Cambodian refugees emigrated from these camps, with about half of this population being relocated to the United States (Mollica, 1994; Southeast Asian Archive, 1999).

\section{Cambodian Initial Adjustment in America}

Upon immigration, the initial reaction of the Cambodian refugees to U.S. society was characterized by confusion, mistrust, and a sense of helplessness (Ong, 2003). To further complicate this difficult transition, the destruction of formal education and society in Cambodia by the Khmer Rouge, incompatible job skills from Cambodia to the United States, and limited exposure to Western ideas and language prior to immigration all contributed to the adjustment challenges of the Cambodian people in the United States. In addition, Cambodian refugees were relocated mostly to large cities, where they were unable to find work using their native vocational skills, which traditionally involved farming and fishing. They also experienced difficulty in adjusting to most aspects of daily life, such as the use of local transportation, obligations regarding formal education for their children, and access to community service providers. Moreover, acts of discrimination were not uncommon experiences for Cambodian refugees, ranging from denial of employment to blatant incidences of hate crime. 
Cambodian cultural tradition differs vastly from mainstream U.S. culture, as well as other Asian cultures (e.g., Ngo \& Lee, 2007; Southeast Asian Archives, 1999). For example, a major adjustment that the Cambodian community has had to make in the United States involves changes to the traditional family structure. The traditional family in Cambodia existed to fulfill several collectivist functions: economic cooperation, emotional support, and a guarantee of assistance in any difficult situation. To accomplish these objectives, the traditional family structure integrated larger groupings of family members than those typically associated with the mainstream U.S. nuclear family, including grandparents, grandchildren, uncles, aunts, cousins, nephews, and nieces who all lived in close proximity to one another. However, the eradication of a large portion of the Cambodian population by the Khmer Rouge, especially of male members, has resulted in the destruction of these extended families (Nguy, 2000). In addition, many of these extended families have been separated due to the relocation process to the United States and elsewhere. Chung, Bemak, and Kagawa-Singer (1998) support the conclusion that the destruction of familial tradition in the Cambodian community is intensified as the family attempts to adjust to U.S. society.

\section{Acculturation}

One important aspect of the Cambodian experience in the United States is the acculturation process. Acculturation has been defined as a mutual change process that occurs when groups and individuals from different cultures come into continuous first-hand contact with one another (Redfield, Linton \& Herskovits, 1936). At the individual level, acculturation may involve a variety of personal changes as reflected in behavior, language, values, and identity. Berry (2003), a leading theorist on acculturation, suggests that stress plays a prominent role in the acculturation process as immigrants/refugees confront new cultural demands and attempt to cope with significant life changes. Furthermore, the stress experienced during the acculturation process can lead to other stressors, including intergenerational conflict, mental health problems, and socioeconomic barriers. For Cambodian refugees, stress experienced during the acculturation process may be particularly intensified because of the dramatic change in cultural context and because of their historical exposure to war and trauma (Chung, 2001; Silka \& Tip, 1994). In turn, stress associated with the acculturative experience can impact various dimensions of well-being.

\section{Intergenerational Conflict}

Another important aspect of the Cambodian experience in the United States is intergenerational conflict, which stems from differences in acculturative experiences of parents and children. Acculturative incongruity occurs frequently within many Asian immigrant families (Dinh \& Nguyen, 2006; Dinh, Sarason, \& Sarason, 1994). Similar to other Asian immigrant parents, Cambodians parents fear that their children are forgetting their native culture and language, while at the same time they want their children to learn English in order to adapt quickly to U.S. society (Mortland, 1996). Extreme difficulties also result when parents are unable to learn English while children are unable to maintain their proficiency in Khmer. The consequence is that different generations in many Cambodian families lose their ability to communicate effectively with each other in their new country. When Cambodian children need to assume responsibilities as family spokespersons because parents or elders are unable to become proficient in English, intergenerational conflict intensifies through the reversal of traditional 
parent-child roles. Intergenerational conflict also results from choices that children need to make in regards to maintaining Cambodian cultural traditions versus assimilating to U.S. societal norms (Earm, 2002; Tan, 2000). Cambodian youth may experience both explicit and subtle pressure from U.S. society, including within the school context (e.g., peers, teachers, etc.), to adopt an identity that is "American" while there is conflicting pressure from their parents and other elders to maintain Cambodian cultural traditions, values, and language in their daily lives, resulting in direct conflict with older family members.

\section{Mental Health Issues}

The demands of coping with acculturative stresses have created difficulty for the emotional adjustment of the Cambodian community in the United States (Keo, 2001; Mollica, Poole, Son, Murray, \& Tor, 1997). As a consequence of the high frequency of exposure to extreme adversity and trauma in Cambodia, dramatic relocation to the United States, and the resulting transformation of Cambodian culture and family, mental health difficulties are widespread in the Cambodian American population. As victims of violence and witnesses to murder, Cambodian refugees commonly report symptoms of depression, post-traumatic stress syndrome, and survivor's guilt. Previous empirical investigations have found that depression and posttraumatic stress disorder (PTSD) constitute the most common psychiatric disorders in refugee populations (Marshall, Schell, Elliot, Berthold, \& Chun, 2005). In one study, 86\% of Cambodians participants met DSM-III-R criteria for PTSD and 80\% met the criteria for depression (Carlson \& Rosser-Hogan, 1993). Even after more than 20 years since the fall of the Khmer Rouge and immigration to the United States, Cambodian Americans are still suffering from extremely elevated rates of depression (51\%) and other mental disorders (Marshall et al., 2005).

With regard to the mental health status of entire families, the emotional distress endured by one family member has been shown to have a significant impact on the remaining family members, especially on children and adolescents. Indeed, Tan (2000) suggests that the widespread emotional trauma in the adult Cambodian population may create an inability for the adult generation to invest themselves in monitoring the development of the younger generation. Consequently, the Cambodian youth population has been found to be at increased risk for mental health problems, such as depression and anxiety (Hsu, Davies, \& Hansen, 2004). Research has further shown that children who live in disadvantaged contexts (e.g., low socioeconomic status) tend to experience more psychological and behavioral difficulties (Hernandez, 1993; Oropesa, \& Landale, 1997). Therefore, in addition to the more extensive mental health problems of the adult Cambodian population, mental health issues among Cambodian youth, including those born in the United States, represent another key factor for consideration in research with this high risk population (Tan, 2000).

\section{Academic-Related Outcomes}

It is important to note that Southeast Asians vary significantly from the aggregated classification of "Asian Americans." In examining the academic success of the entire group, Southeast Asians experience lower rates of achievement than White Americans, with more than 38\% lacking a high school diploma (White $=16.6 \%$ ) and $8 \%$ having no formal schooling (White $=0.9 \%$ ) (Chang \& Le, 2005; Niedzwiecki \& Duong, 2004). In examining the academic success of Cambodian Americans alone, however, the U.S. 2000 Census data reveals that of the current 
adult population (ages 25 and over), 52.9\% lack a high school diploma, 26.2\% have no formal education, and only 9.1\% have acquired a college degree. Because Cambodian Americans tend to experience considerable academic challenges, as indicated by low rates of educational attainment and high rates of high school drop-out, it is imperative for social scientists to investigate the correlates and predictors of academic-related outcomes and begin to address the educational needs of Cambodian American youth. As academic success involves much more than just grades or grade point average, research should also include other important dimensions of academic outcomes, such as students' educational aspirations, their beliefs in the utility of education, and/or their sense of school belongingness.

Past research with other ethnic youth samples has found a relationship between emotional problems and trouble at school (Salyer \& Holmstrom, 1991; Weinberg et al., 1989). Cambodian American students also appear to be fitting into this pattern, as their tendency to withdraw more from classroom activities has been attributed to emotional factors, which may stem from the mental and physical hardships endured by the entire Cambodian community prior to immigration (Kinzie \& Sack, 2002; Nguy, 2000). Even when Cambodian children are born in the United States, these barriers still exist for their immigrant parents, which can hamper parents' ability to contribute to their children's academic progress, and in turn impacts the children's own educational success (Nguy, 2000; Zhou, 1997). For example, Cambodian American students have been found to have increased difficulties with physical and mental health issues, which affect their ability to be engaged in academic activities and social obligations that are an integral part of the school experience. Thus, as a method of coping, many Cambodian students withdraw from the academic environment, which consequently can impact their grades as well as other dimensions of academic success. Consistent with this observation, research reveals that Cambodian American students are performing below the average U.S. student (Nguy, 2000). Another study (Tan, 2000) found that the grade point averages of Cambodian adolescents were much lower than those of White students. Emotional/mental health issues combined with other social, cultural, and/or environmental barriers (e.g., challenges associated with adjustment to U.S. society, language barriers, differences in educational systems between U.S. and Cambodia, poverty, etc.) can result in a decreased level of self-confidence in academic abilities and achievement, as well as an increased level of alienation from the school community among Cambodian American students (Congress \& Lynn, 1994; Drachman, 1992; Goldberg, 1999; Hsu et al., 2004).

The acculturative incongruity between Cambodian American parents and their children is potentially another stressor affecting academic-related outcomes. When examining the effects of acculturative-related factors on educational achievement, parent-child relationships are strongly associated with academic outcomes (Portes \& MacLeod, 1999; Portes \& Rumbaut, 2001). For example, research with other immigrant populations has found students' grade point average, educational aspirations, and academic expectations to significantly increase with family cohesion and significantly decrease with parent-child conflict. Similarly, dissonant acculturation, as measured by parent-child conflict, has been shown to have a negative effect on academic achievement. This effect tends to manifest itself quite early-longitudinal research with immigrant families has found that children who experienced parent-child conflict in earlier grades were much less likely to do well academically in later years (Portes \& Rumbaut, 2001). Therefore, research with Cambodian American youth also should include an assessment of intergenerational conflict as it can impact the quality of their academic experiences. 


\section{Importance of Demographic Factors}

The economic and social resources available to children through their families also have been shown to have an effect on students' success in school (Zhou, 1997). Thus, the economic stressors that are common in the Cambodian American community, such as living in poverty, inhabiting dangerous neighborhoods, and parents who are forced to work long hours to make ends meet, all can have a negative impact on Cambodian American children (Nguy, 2000; Wood, 2001). In addition, other demographic factors, such as gender and immigrant status can play important roles in influencing academic-related outcomes. Therefore, it is important to consider the effects of these demographic characteristics in order to understand the contextual challenges that may exist in the lives of Cambodian American youth.

\section{Purpose of Current Study}

The purpose of this study was to examine the acculturative and psychosocial predictors of academic-related outcomes among Cambodian American high school students. Cambodian students were chosen to be the main focus of this study because these youth are at very high risk for school drop-out among the entire Asian American population (Wright, 1998). There are clear consequences involved in the failure to address the challenges and barriers to educational achievement within the Cambodian American youth population. By examining the factors that may hinder or promote educational achievement among Cambodian youth in the American school system, findings from this study can help to inform school personnel, Cambodian parents, and prevention program developers, about the ways in which academic success can be facilitated among these students.

The primary research question is: To what extent do (a) acculturative variables (Cambodian cultural orientation and Anglo/White cultural orientation), (b) psychosocial variables (intergenerational conflict and depression), and (c) specific demographic variables (age, gender, immigrant status, and socioeconomic status) predict academic-related outcomes among Cambodian American high school students? In addition, correlations among the predictor variables (Cambodian and Anglo/White cultural orientations, intergenerational conflict, depression, and demographic characteristics) and correlations among the outcome variables (grade point average, educational aspirations, beliefs in the utility of education, and psychological sense of school membership) were examined separately.

\section{Method}

\section{Participants}

The sample included 163 Cambodian American students (57\% girls and 43\% boys) from a large urban public high school, located in the state of Massachusetts. The mean age among these students was 16.08 ( $S D=1.41$ ), ranging from ages 13 to 20 . There were $25 \%$ ninth-graders, $27 \%$ tenth-graders, $28 \%$ eleventh-graders, and $20 \%$ twelfth-graders. With regard to immigrant status, $74 \%$ were born in the United States and $26 \%$ were born outside the United States. Students reported the majority of their mothers and fathers were born outside the United States; 99\% and $98 \%$, respectively. As a proxy measure of socioeconomic status, $50 \%$ of students reported 
parental home ownership and 50\% reported parental non-home ownership (e.g., renting apartment/house).

\section{Procedure}

With approval from the school district's superintendent, high school principal, district school committee, and university institutional review board, recruitment of Cambodian American students took place through advisory/home rooms and Khmer language classes at the high school during the Spring of 2006. Through school personnel, including a bilingual Cambodian liaison and a trained bilingual Cambodian research assistant, students in all four grade levels $\left(9^{\text {th }}-12^{\text {th }}\right)$ were encouraged to participate, with clear instructions that participation would be completely voluntary. A cover letter, along with an informed consent form and a returned stamped envelope, were mailed directly to parents as well as sent home with students from school. The cover letter and informed consent form were translated from English to Khmer and back-translated from Khmer to English, explaining the purpose and procedure of the study; both language versions were sent to parents. Because recruitment of ethnic minority students in a public high school setting can be quite challenging, recruitment packages were sent to 500 Cambodian American parents with the goal of 200 student participants for the study. The response rate was 38\%, which was low but not unexpected. Only students who had one or both parents' permission and who also consented to being part of the study were allowed to participate in a survey session. Each student received a free movie ticket for participation in this study.

Small-group survey sessions, lasting approximately 30 minutes, were held at the high school both during the school day and after school hours. Students were assured that their responses to the survey would be anonymous and were instructed to leave their names off the surveys for this purpose. This information was provided to students both verbally and in writing, to ensure understanding for all students. The self-report survey was used to assess Cambodian cultural orientation, Anglo/White cultural orientation, intergenerational conflict, depression, academic-related outcomes (GPA, educational aspirations, beliefs in utility of education, and psychological sense of school membership), and demographic information. Use of self-reports has been shown to be reliable in research with diverse adolescent groups (e.g., Wills \& Cleary, 1997).

\section{Instruments}

\section{Acculturation/Cultural Orientation}

The General Ethnicity Questionnaire (GEQ) (Tsai, Ying, \& Lee, 2000), namely the Chinese cultural orientation and Anglo/White cultural orientation scales, were adapted for this study. The GEQ is a bidimensional measure of acculturation as opposed to the typical unidimensional measures that only assess for immersion into the Anglo/White mainstream U.S. culture. Anglo/White cultural orientation was included in this study, as opposed to other ethnic or cultural groups' orientations, because it is the dominant culture in the United States to which immigrant students face considerable assimilation pressures. Due to concerns about the length of the survey, only 10 items were selected from each of the respective 39-item scales of the GEQ. Only the items in the Chinese cultural orientation scale were slightly revised to reflect the Cambodian cultural orientation (e.g., changing "I am proud of Chinese culture" to "I am proud of 
Cambodian culture.”) Each item in the GEQ was accompanied by a 5-point Likert-type scale, ranging from (1) "strongly disagree" to (5) "strongly agree." Higher scores reflected higher levels of immersion into Cambodian culture or Anglo/White culture. Sample items include: "I would prefer to live in a Cambodian American (Anglo/White American) community" and "I am familiar with Cambodian (Anglo/White American) cultural practices and customs.” Internal reliabilities for the original GEQ scales were high (.92). In this study, the internal reliability coefficients for the Cambodian cultural orientation and Anglo/White cultural orientation scales were .81 and .91 , respectively.

\section{Intergenerational Conflict}

The Dinh Intergenerational Conflict Inventory (DICI) (Dinh, 2005; see Appendix) was developed for this study to assess intergenerational conflict between Cambodian American parents and children. It is a 10-item measure, with a 5-point Likert-type scale, ranging from (1) "not true at all" to (5) "very much true." Sample items include: "My parents believe I have become too Americanized," "My cultural values are the same as my parents' cultural values," and "I disagree with my parents about traditional Cambodian family roles." In this study, the internal reliability coefficient for the DICI was .71.

\section{Depression}

The Center for Epidemiological Studies-Depression (CES-D) scale (Radloff, 1977) was used to assess depression. It is a 20-item measure, utilizing a 4-point Likert-type scale, ranging from (1) "rarely or none of the time" to (4) "most or all of the time." Sample items include: "I felt that I could not shake off the blues even with help from my family or friends," "I had trouble keeping my mind on what I was doing," and "I thought my life had been a failure." The CES-D scale has good internal reliability (.86) across diverse subgroups (Orme, Reis, \& Herz, 1986). In this study, the internal reliability coefficient for the CES-D was .86.

\section{Academic-Related Outcomes}

Students' current grade point average (GPA) was assessed with one item, asking students to indicate their GPA on a grading scale that was the standard in the participating high school. The scale ranged from "below 65" to "95-100" with higher scores indicating higher GPAs.

Educational aspirations were assessed through the following three questions: "How far do your parents or guardians want you to go in school?," "How far would you like to go in school?," and "How far do you think you will actually go in school?" The response scale to these three questions includes: (1) "finish some high school," (2) "graduate from high school," (3) "graduate from a 2-year college," (4) "graduate from a 4-year college," and (5) "graduate from a law, medical, or graduate school." In this study, these three questions were combined into one summary score and had an internal reliability coefficient of .86.

The Beliefs in the Utility of Education (BUE) scale assessed students' attitudes toward education (Fuligni, 2001). It is a 5-item measure, utilizing a 5-point Likert-type scale, ranging from (1) "not at all true for me" to (5) "very true for me." Sample items include: "Going to college is necessary for what I want to do in the future" and "Doing well in school is the best 
way for me to succeed as an adult.” This measure has good internal reliability (.88). In this study, the internal reliability coefficient for the BUE was .86.

The Psychological Sense of School Membership measure (PSSM) (Goodenow, 1993) was used to assess how connected, accepted, and supported participants feel at their school. This 18-item measure utilizes a 5-point Likert-type scale, ranging from (1) "not at all true" to (5) "completely true." Sample items include: "Other students in this school take my opinions seriously," "Most teachers here are interested in me," and "I wish I were in a different school." The PSSM's internal reliability (.88) has been shown to be good across diverse samples. In this study, the internal reliability coefficient for the PSSM was .85.

\section{Demographic Information}

As part of the survey, a short questionnaire was used to collect key demographic information, including participant's age, gender, grade level, and immigrant status. In addition, information was also collected about the characteristics of parental socioeconomic/employment status and other family demographic information. With regard to parental socioeconomic status (SES), parental home ownership was assessed as a proxy measure of SES and was included in this study because students were more likely to have knowledge of their parents' home ownership status than other aspects of SES, such as the level of total household income or level of parental education or type of employment.

\section{Results}

The main goal of this study was to examine acculturative and psychosocial predictors of academic-related outcomes among Cambodian American high school students, using multiple hierarchical regression analysis. Specific demographic characteristics were also included in the predictive model. Prior to conducting the regression analysis, correlational analysis was used to examine separately the relationships among the predictor and outcome variables.

\section{Relationships among Predictor and Outcome Variables}

\section{Predictor Variables}

In Table 1, there were few statistically significant relationships among the predictor variables. Immigrant status was positively associated with socioeconomic status $(p<.01)$, indicating that U.S.-born students reported more parental home ownership than did their foreign-born counterparts. The Cambodian cultural orientation scale was positively associated with the Anglo/White cultural orientation scale $(p<.01)$, but negatively associated with intergenerational conflict $(p<.01)$. Finally, intergenerational conflict was positively associated with depression $(p$ $<.01)$. In sum, participants who adopted a higher Cambodian orientation also adopted a higher Anglo/White orientation, suggesting a bicultural orientation. Furthermore, higher Cambodian orientation was related to lower intergenerational conflict, which in turn was related to lower depression level. These findings indicate that there are positive benefits for students to maintain a Cambodian cultural orientation. 
Table 1

\begin{tabular}{|c|c|c|c|c|c|c|c|c|}
\hline \multicolumn{9}{|c|}{ Correlations among Predictor Variables } \\
\hline & 1 & 2 & 3 & 4 & 5 & 6 & 7 & 8 \\
\hline 1. Age & ---- & -.04 & -.14 & -.11 & .08 & .06 & -.01 & -.05 \\
\hline 2. Gender & & ---- & .09 & -.03 & .07 & .05 & -.10 & -.15 \\
\hline 3. Immigrant Status & & & ---- & $.23 * *$ & -.02 & .07 & .00 & .05 \\
\hline 4. SES & & & & ---- & .01 & .05 & -.09 & -.05 \\
\hline 5. GEQ Cambodian & & & & & --- & $.22^{* *}$ & $-.24^{* *}$ & .01 \\
\hline 6.GEQ Anglo/White & & & & & & ---- & .04 & -.12 \\
\hline 7. DICI & & & & & & & ---- & $.20^{* *}$ \\
\hline 8. CES-D & & & & & & & & ---- \\
\hline Mean & 16.08 & 1.43 & 1.74 & 1.50 & 3.81 & 3.12 & 2.60 & 1.91 \\
\hline$S D$ & 1.41 & 0.50 & 0.44 & 0.50 & 0.55 & 0.68 & 0.66 & 0.48 \\
\hline
\end{tabular}

Note. $N=$ 163. Gender ( 1 = female; 2 = male); Immigrant Status $(1=$ foreign-born; 2 = U.S.-born); SES = Socioeconomic Status ( 1 = parents' non-home ownership; 2 = parents' home ownership); GEQ Cambodian = General Ethnicity Questionnaire Cambodian Orientation; GEQ Anglo = General Ethnicity Questionnaire Anglo/White Orientation; DICI = Dinh Intergenerational Conflict Inventory; CES-D = Center for Epidemiological Studies - Depression. ${ }^{* *} p<.01$.

\section{Outcome Variables}

In Table 2, all of the correlation coefficients were statistically significant. For example, grade point average (GPA) was positively related to educational aspirations $(p<.001)$, beliefs in the utility of education (BUE) $(p<.05)$, and psychological sense of school membership (PSSM) $(p<$ $.001)$. PSSM also was positively related to educational aspirations $(p<.001)$ and BUE $(p<.01)$. In other words, participants who reported a higher GPA also reported higher educational aspirations, stronger beliefs in the utility of education, and a stronger sense of school membership. Furthermore, participants who experienced a stronger sense of school membership also reported higher educational aspirations. Thus, sense of school membership, educational aspirations, beliefs in the utility of education, and GPA are all related for these students. 
Table 2

\begin{tabular}{lllll}
\hline Correlations among Outcome Variables & \multicolumn{5}{l}{} \\
\hline & 1 & 2 & 3 & 4 \\
\hline 1. Grade Point Average & ---- & $.39^{* * *}$ & $.17^{*}$ & $.32^{* * *}$ \\
2. Educational Aspirations & & $---3^{* * *}$ & $.43^{* * *}$ & $.26^{* * *}$ \\
3. Beliefs in Utility of Education & & & --- & $-{ }^{---}$ \\
4.Psychological Sense of School & & & & \\
$\quad$ Membership & & & & \\
\hline Mean & 5.37 & 3.79 & 4.54 & 3.60 \\
$S D$ & 1.48 & 0.84 & 0.60 & 0.58 \\
\hline
\end{tabular}

Note. $N=163 .{ }^{*} p<.05 .{ }^{* * *} p<.001$.

\section{Predicting Academic-Related Outcomes}

Hierarchical multiple regression analyses were used to predict academic-related outcomes. The prediction model included an examination of (a) demographic variables in step one and (b) acculturative and psychosocial variables in step two. Table 3 shows the results for the prediction of GPA, educational aspirations, beliefs in utility of education, and psychological sense of school membership.

\section{Predicting Grade Point Average (GPA)}

Demographic variables altogether did make a significant contribution to the variance for GPA, with immigrant status as a significant correlate. Students who were born in the United States reported a lower GPA than those born outside the United States. With regard to acculturative and psychosocial variables, especially the Anglo/White cultural orientation scale of the GEQ and depression, these variables significantly contributed to the prediction of GPA. Anglo/White cultural orientation was positively associated with GPA whereas depression was negatively associated with GPA, indicating that a higher Anglo/White orientation predicted a higher GPA, while a higher level of depression predicted a lower GPA. Overall, the predictor variables contributed $29 \%$ of the variance in GPA.

\section{Predicting Educational Aspirations}

Demographic variables were non-significant in their contribution to the prediction of educational aspirations, even though immigrant status was a significant correlate of this outcome, with U.S.born students reporting less educational aspirations than did their foreign-born counterparts. Acculturative and psychosocial variables, especially Anglo/White cultural orientation, significantly contributed to the prediction of educational aspirations. Similar to GPA, participants with higher Anglo/White orientations were found to have higher educational aspirations. Overall, the predictor variables contributed $24 \%$ of the variance in educational aspirations. 
Table 3

\begin{tabular}{|c|c|c|c|}
\hline \multicolumn{4}{|l|}{ Predicting Academic-Related Outcomes } \\
\hline Step/Variable & $\beta$ & $R_{\text {change }}^{2}$ & $F_{\text {change }}$ \\
\hline \multicolumn{4}{|c|}{ Grade Point Average $\left(R_{\text {total }}^{2}=.29, F(8,154)=7.89 * * *\right)$} \\
\hline 1. Demographic Variables & & .10 & $4.52 * *$ \\
\hline Age & -.04 & & \\
\hline Gender & -.09 & & \\
\hline Immigrant Status & $-.32 * * *$ & & \\
\hline Socioeconomic Status & .01 & & \\
\hline 2. Acculturative \& Psychosocial Variables & & .19 & $10.20 * * *$ \\
\hline GEQ Cambodian Orientation & .07 & & \\
\hline GEQ Anglo/White Orientation & $.27 * * *$ & & \\
\hline Intergenerational Conflict & -.08 & & \\
\hline Depression & $-.28 * * *$ & & \\
\hline \multicolumn{4}{|c|}{ Education Aspirations $\left(R_{\text {total }}^{2}=.24, F(8,154)=6.19 * * *\right)$} \\
\hline 1. Demographic Variables & & .04 & 1.73 \\
\hline Age & -.06 & & \\
\hline Gender & -.09 & & \\
\hline Immigrant Status & $-.19 *$ & & \\
\hline Socioeconomic Status & .12 & & \\
\hline 2. Acculturative \& Psychosocial Variables & & .20 & $10.24 * * *$ \\
\hline GEQ Cambodian Orientation & -.02 & & \\
\hline GEQ Anglo/White Orientation & $.43^{* * *}$ & & \\
\hline Intergenerational Conflict & -.07 & & \\
\hline Depression & -.09 & & \\
\hline \multicolumn{4}{|c|}{ Beliefs in Utility of Education $\left(R_{\text {total }}^{2}=.13, F(8,154)=2.85^{* *}\right)$} \\
\hline 1. Demographic Variables & & .03 & 1.30 \\
\hline Age & .01 & & \\
\hline Gender & $-.18 *$ & & \\
\hline Immigrant Status & -.03 & & \\
\hline Socioeconomic Status & .04 & & \\
\hline 2. Acculturative \& Psychosocial Variables & & .10 & $4.30 * *$ \\
\hline GEQ Cambodian Orientation & $.23 * *$ & & \\
\hline GEQ Anglo/White Orientation & .08 & & \\
\hline Intergenerational Conflict & -.12 & & \\
\hline Depression & -.10 & & \\
\hline \multicolumn{4}{|c|}{ Psychological Sense of School Membership $\left(R_{\text {total }}^{2}=.43, F(8,154)=14.83^{* * *}\right)$} \\
\hline 1. Demographic Variables & & .09 & $4.06 * *$ \\
\hline Age & $.20 * *$ & & \\
\hline Gender & -.05 & & \\
\hline Immigrant Status & -.12 & & \\
\hline Socioeconomic Status & .07 & & \\
\hline 2. Acculturative \& Psychosocial Variables & & .34 & $23.29 * * *$ \\
\hline GEQ Cambodian Orientation & $.14^{*}$ & & \\
\hline GEQ Anglo/White Orientation & $.28 * * *$ & & \\
\hline Intergenerational Conflict & -.05 & & \\
\hline Depression & $-.44 * * *$ & & \\
\hline
\end{tabular}

Note. Gender (1 = female, 2 = male); Immigrant Status ( 1 = foreign-born; 2 = U.S.-born); Socioeconomic Status (1 = parents' non-home ownership; 2 = parents' home ownership); GEQ = General Ethnicity Questionnaire. $R_{\text {change }}^{2}=$ the percentage of variance accounted for by variables when entered into the regression equation at that step; $F_{\text {change }}=$ $F$ value associated with $R_{\text {change }}^{2}$ at that step; $R_{\text {total }}^{2}=$ the total amount of variance predicted jointly by all of the variables entered into the regression equation. ${ }^{*} p<.05 .{ }^{* *} p<.01 .{ }^{* * *} p<.001$.

Predicting Beliefs in Utility of Education (BUE)

The contribution of demographic variables was statistically non-significant, even though gender was a significant correlate, with male students being less likely than female students to believe in the utility of education. The contribution of acculturative and psychosocial variables were 
statistically significant, but only the Cambodian cultural orientation scale was a significant correlate of BUE, indicating that a higher Cambodian cultural orientation predicted stronger beliefs in the utility of education. Overall, the predictor variables contributed $13 \%$ of the variance in students’ BUE.

\section{Predicting Psychological Sense of School Membership (PSSM)}

The contributions of demographic variables and acculturative/psychosocial variables were all statistically significant. Age was a significant correlate of PSSM, such that being older predicted a stronger sense of school membership. Both the Cambodian and Anglo/White cultural orientation scales were positively associated with PSSM, with those higher on Cambodian or Anglo/White orientation scales reporting stronger school membership. Depression was negatively associated with PSSM, indicating that participants who had a higher depression level reported a lower sense of school membership. Overall, the predictor variables contributed $43 \%$ of the variance in students' PSSM.

\section{Discussion}

The primary focus of this study was to investigate the roles of acculturative and psychosocial variables in predicting academic-related outcomes among Cambodian American high school students. Key demographic variables (age, gender, immigrant status, and SES) also were included in the predictive models. Acculturative variables were Cambodian cultural orientation and Anglo/White cultural orientation while psychosocial variables were intergenerational conflict and depression. Academic-related outcomes included GPA, educational aspirations, beliefs in the utility of education, and psychological sense of school membership. As a secondary focus, the interrelationships among the predictor and outcome variables were examined separately. Overall, the main results point to the importance of acculturative and psychosocial variables in the prediction of academic-related outcomes. Demographic variables, in general, played a minor role. The results also point to the importance of examining the interrelationships among academic-related outcomes.

There were few significant associations among the predictor variables. Cambodian cultural orientation was positively associated with Anglo/White cultural orientation, suggesting that Cambodian American students in this study tended to adopt a bicultural mode of acculturation (Berry, 2003). Biculturalism, often seen in adolescents of immigrant background, is defined as competence in alternating between two cultural orientations - their native culture and the majority/dominant culture of the community in which they are living (LaFramboise, Coleman, \& Gerton, 1993). For Cambodian American adolescents, adoption of biculturalism is perhaps a must because of their competing exposures to both home and school cultures. Indeed, previous research indicates that bicultural individuals have more beneficial experiences than those with a monocultural orientation, including better psychological well-being (Berry, Phinney, Sam, \& Vedder, 2006; LaFromboise et al., 1993; Lambert \& Taylor, 1990). Cambodian cultural orientation was negatively associated with intergenerational conflict, which is consistent with previous research (Dinh \& Nguyen, 2006). Students whose cultural orientation is more congruent with their parents' cultural orientation experience less parent-child conflict in cultural values/behavior. This finding underscores the importance of investigating the degree of differential experiences of acculturation between parents and children in research with immigrant families (Buki, Ma, Strom, \& Strom, 2003; Santisteban \& Mitrani, 2003). 
Intergenerational conflict was found to be associated with depression, an interesting finding considering that both depression and conflict with parents tend to increase during adolescence (Laible, Carlo, \& Raffaelli, 2000). This finding is consistent with previous research involving other ethnic youth samples, showing that adolescents who did not experience strong, secure relationships with parents reported higher levels of depression (Laible et al., 2000). Within immigrant families, intergenerational conflict has been shown to be a risk factor for psychological distress among both parents and children (Aldwin \& Greenberger, 1987; Yao, 1985; Ying \& Tracy, 2004). The stress associated with intergenerational conflict can be particularly heightened for immigrant families of Asian background that highly value intergenerational cohesion. Therefore, depression may be one of the negative consequences of intergenerational conflict for Cambodian American adolescents as they experience conflicting home and school cultures, finding themselves unable to cope with the stress.

Not surprisingly, the intercorrelations among the academic-related outcomes were statistically significant. However, the degrees of associations among these variables were generally modest, suggesting that while these variables are interrelated, they are measuring somewhat different aspects of academic experiences, attitudes, perceptions, and achievement. These results highlight the importance of assessing multiple dimensions of academic outcomes that can yield a more comprehensive understanding of the factors underlying students' academic performance. Academic success encompasses much more than just grade point average; it also encompasses that sense of belongingness to a school community and feelings of acceptance and respect by peers and teachers, as well as a strong belief that one can go far in school and that education can lead to positive life outcomes. In addition to helping students increase their GPAs, support and attention should be directed at increasing the levels of these other factors, such as students' educational aspirations and psychological sense of school membership, which also constitute the overall quality of academic success (Hagborg, 1998; Sanchez, Colon, \& Esparza, 2005). This conclusion is supported by previous research involving Cambodian American students, revealing that students' attitudes about school were significantly related to academic achievement, measures of GPA, school-related behaviors, and educational aspirations (Chang \& Le, 2005; Goldberg, 1999).

In the prediction of academic-related outcomes, acculturative and psychosocial variables together were especially important predictors, contributing to sizable portions of the variance in three of the four outcomes. Among the acculturative variables, both Cambodian and Anglo/White cultural orientations were important correlates, namely the former played a significant role in students' beliefs in the utility of education and psychological sense of school membership while the latter played a significant role in students' grade point average, educational aspirations, and PSSM. In other words, a Cambodian cultural orientation or an Anglo/White cultural orientation independently has academic benefits for students. Taken together, these results suggest that immersion in Cambodian culture as well as immersion in Anglo/White culture can facilitate academic success, again pointing to the benefits of adopting a bicultural identity. This and other results in this study run counter to the notion of Englishimmersion-only movement in school that is advocated by various segments of U.S. society. When immigrant/refugee children lose their native language they also lose significant parts of their native culture as language is a major vehicle for absorbing and maintaining cultural values and behaviors. If we are indeed serious about improving the academic success of immigrant youth, then the promotion of biculturalism or multiculturalism in schools and within society should be more the norm. Furthermore, biculturalism, as opposed to just assimilation, would 
facilitate a better quality of parent-child relationship as children's cultural orientation is more congruent with their parents', thus reducing the severity of intergenerational conflict.

Among the psychosocial variables, depression was an important correlate of academicrelated outcomes, especially for GPA and psychological sense of school membership. These findings are consistent with previous studies, linking depression to poor school performance and low levels of academic achievement (Andrews \& Wilding, 2004; Shahar et al., 2006). Previous research also showed that Southeast Asian children tend to internalize societal negative expectations, which can result in low expectations for future academic success (Shields \& Behrman, 2004; Yang, 2004). The results from this study, as well as our general knowledge of the historical trauma experienced by the whole Cambodian American community, suggest that in addition to acculturative factors, mental health issues are another dimension of adjustment that warrants serious consideration when examining the academic performance of Cambodian American adolescents. Although intergenerational conflict was not a significant predictor of academic-related outcomes, it is important to note that it was significantly related to both Cambodian cultural orientation and depression so its effects may have been overshadowed by these two variables.

Demographic variables altogether played a minor role in the prediction of academicrelated outcomes. In two of the four outcomes, their contribution to the variance was statistically non-significant. Nonetheless, gender was found to be a significant correlate of beliefs in the utility of education, with male students being less likely than female students to have stronger beliefs in the utility of education. While this gender difference was not found for other academic outcomes in this study, it is consistent with previous findings regarding lower academic expectations and progress in males from other minority and immigrant youth groups (Feliciano \& Rumbaut, 2005; Fuligni \& Witkow, 2004). Furthermore, immigrant status appears to be an important demographic variable, indicating better academic-related outcomes among foreignborn Cambodian American students. These results are consistent with numerous previous studies, showing that adolescents from various immigrant populations, over time and generations in the United States, experience a decline in student GPA (Kao \& Tienda, 1995; Rumbaut \& Ima, 1988; Suarez-Orozco, 1989). It has been demonstrated that recent immigrant families strongly reinforce the value of educational achievement for their children, resulting in higher academic aspirations and performance by foreign-born adolescents as compared to their U.S.born counterparts (Portes \& Rumbaut, 2001; Zhou, 1997). Perhaps, underlying this strong value for education is the fact that many recent immigrant parents, who tend to work in poor paying jobs and/or hard laboring jobs, often convey to their foreign-born children that they can do better and that education is the main gateway to better career opportunities and economic stability.

\section{Limitations of the Present Study}

There are a few limitations in this study that should be taken into consideration when thinking about future research in this area. One limitation is that the information gathered from students was from self-reports, which may have introduced some biases into the results. Due to both financial and time constraints involved in this study, it was impossible to gather information about the students from multiple sources, such as teachers' perspectives on student academic performance and parents' perspectives on intergenerational conflict and educational aspirations for their children. However, it is important to note that the results from this study are consistent with findings from previous studies and the use of self-reports has been demonstrated to produce 
reliable results in research with minority adolescent samples (Wills \& Cleary, 1997). Another limitation in this study involves the participant sample, comprising solely of high school Cambodian American students. Therefore, the results might not apply to younger or older Cambodian American students who are at different developmental stages, nor to other Asian or Southeast Asian youth populations. An additional limitation is that the response rate for participant recruitment was low, potentially introducing some selection bias into this study. Finally, this study was cross-sectional in design, which did not provide a developmental perspective on the acculturation process or establish a causal understanding of the relationships of acculturative and psychosocial factors to academic-related outcomes.

\section{Implications for Future Research and Interventions}

Despite the limitations, findings from this study provide important implications for future research and intervention programs. Future research with Cambodian American youth should further examine the processes by which a bicultural identity is adopted by these youth as there are potential benefits associated with this mode of adaptation. In other words, what are the dynamics that are involved as they integrate aspects of both cultures and who or what factors play important facilitating or hindering roles in this process? In addition, as the United States is a country of diverse ethnic and cultural groups, the inclusion of assessments of other salient cultural orientations (e.g., African American cultural orientation, Latino cultural orientation, etc.) would yield richer information about the dynamics involved in immigrant youth's adjustment and multicultural adaptation. Future research also should focus on intergenerational conflict and its antecedents as it is connected to the acculturation experience. Because students' depression was shown to be a significant correlate of academic-related outcomes, the impact of mental health problems on academic success and the ways in which they are linked to intergenerational conflict should be considered in future research. The dynamic relationship between acculturative issues and academic success is a complex process that requires complex research approaches. Future research should include additional variables, such as peer influence and network, parental mental health status and other family factors, and additional contextual variables (e.g., migration and resettlement histories, ethnic make-up of neighborhoods, etc.), in the predictive model. The use of longitudinal designs and multiple informants would certainly provide a richer understanding of the academic experiences of Cambodian American adolescents.

In sum, the results of this study, as well as those from previous research, suggest that acculturative, intergenerational, and mental health issues are all dimensions of adjustment that warrant serious consideration when investigating academic performance among Cambodian American adolescents. Therefore, findings from this study can help to inform developers of school-based and family-based prevention and intervention programs focusing on the academic needs of Cambodian American students. Such programs should include components that address the stress associated with the acculturative experience, including the stress associated with intergenerational conflict, and acknowledge the benefits that come from facilitating the development of a bicultural identity. The main goal here is not necessarily to help students assimilate quickly to the Anglo/White American culture, but to assist them in coping with the struggle involved in living within two cultures. For example, because school is an established community institution that is able to provide support to local areas, incorporating culturally relevant curriculum and programming into the school setting is one way that Cambodian American students may be able to maintain connections to their native culture (Larson, Gomby, 
Shiono, Lewit, \& Behrman, 1992; Ngo \& Lee, 2007). By discovering the balance between Cambodian culture and mainstream Anglo/White culture, they can be successful both at school and at home.

Multifaceted interventions for Cambodian students become more effective when familybased supports are brought into the school setting (Larson et al., 1992). The employment of bilingual social workers and parent advocates has been shown to be an effective approach to bridging the gap between the school and Southeast Asian family members. Furthermore, successful programs for Cambodian American students should include additional components that address their mental health needs, as mental health concerns are intricately interwoven within the Cambodian American community due to the historical context of war and genocide. Finally, these programs should place particular emphasis on the educational needs of U.S.-born Cambodian adolescents, as they appear to experience less success in their academic endeavors and more disconnection from their school community.

This study focused on the academic experiences of Cambodian American high school students by examining the acculturative and psychosocial factors that may serve as significant predictors. As Cambodian Americans are an understudied population, this study contributes to the limited knowledge about the life experiences of Cambodian American adolescents who are living within two different cultures. Still, much more information is needed to further our understanding of the acculturative and academic challenges that exist for Cambodian American students because their academic success is important to their overall well-being, as well as to the well-being of the whole Cambodian American community.

\section{Acknowledgements}

This study was supported, in part, by grants from the Council on Diversity and Pluralism, University of Massachusetts Lowell, and the Patrick J. Mogan Cultural Center's Scholar in the City Award, Lowell, Massachusetts, awarded to the first author. The authors would like to thank the Cambodian American student participants as well as school administrators and staff for their collaboration and help on this project. We would like to extend a special thank you to Mr. Samkhann Khoeun for his invaluable research assistance and his knowledge of the Cambodian American community.

\section{About the Authors}

Khanh T. Dinh, PhD. Dr. Dinh is an Associate Professor of Psychology at the University of Massachusetts Lowell. She received her doctorate in clinical psychology from the University of Washington, Seattle. Dr. Dinh's primary research interests are in the area of immigrant psychology and communities, pertaining to acculturation and psychosocial adjustment of Asian and Latina/o immigrant families and youth. She served as a Research Fellow for the Institute for Asian American Studies at the University of Massachusetts Boston and as a Scholar-in-the-City for the Patrick J. Mogan Cultural Center in Lowell. Dr. Dinh is a recipient of an NIH National Health Disparities Research Service Award and a co-recipient of a grant award from the American Psychological Association: Commission on Ethnic Minority Recruitment, Retention and Training in Psychology. Department of Psychology, University of Massachusetts Lowell, 870 Broadway Street, Lowell, MA 01854, United States. Email: khanh_dinh@uml.edu. Phone: 1-978-934-3916; Fax: 1-978-934-3074 
Traci L. Weinstein, M.A. Ms. Weinstein received her Master's degree in Community Social Psychology from the University of Massachusetts Lowell. She is currently pursuing a doctoral degree in Community \& Prevention Research at the University of Illinois at Chicago. Ms. Weinstein's experiences working as a teacher and volunteer with inner city high school students has helped to shape her research interests. She is interested in investigating ways to promote academic achievement for all immigrant and minority youth, especially those who are serviced in substantially separate public school settings such as ELL/ESL and Special Education programs. Department of Psychology, University of Illinois at Chicago, Behavioral Sciences Building (M/C 285), 1007 West Harrison Street, Chicago, IL 60607, United States. Email: tweins2@uic.edu

Su Yeong Kim, Ph.D. Dr. Kim is an Assistant Professor in the Department of Human Ecology, Division of Human Development and Family Sciences at the University of Texas at Austin. She received her doctorate in Human Development from the University of California, Davis. Her research interests include the role of cultural and family contexts that shape the development of adolescents in immigrant and minority families in the U.S. Department of Human Ecology, Division of Human Development and Family Sciences, University of Texas at Austin, 1 University Station A2700, Austin, TX, 78712. Email: sykim@prc.utexas.edu

Ivy K. Ho, Ph.D. Dr. Ho is an Assistant Professor of Psychology at the University of Massachusetts Lowell. She received her doctorate in Clinical Psychology, with a specialization in Health Psychology, from the University of Louisville. She completed a pre-doctoral internship in Medical Psychology at the University of Florida Health Science Center, and a post-doctoral fellowship in Pediatric Pain Psychology at Cincinnati Children's Hospital Medical Center. Her research interests are in health psychology, psychophysiology, and the associations between victimization and physical health among women. Dr. Ho is a co-recipient of a grant award from the American Psychological Association: Commission on Ethnic Minority Recruitment, Retention and Training in Psychology. Department of Psychology, University of Massachusetts Lowell, 870 Broadway Street, Lowell, MA 01854, United States.Email: ivy_ho@uml.edu 


\section{Appendix}

\section{DINH INTERGENERATIONAL CONFLICT INVENTORY (DICI)}

This questionnaire includes a number of statements about issues that may occur in your family. Please carefully read each statement and rate to which extent this is true for you and your parents.

\begin{tabular}{|ccccc|}
\hline 1 & 2 & 3 & 4 & 5 \\
$\begin{array}{c}\text { Not at all } \\
\text { true }\end{array}$ & $\begin{array}{c}\text { Slightly } \\
\text { true }\end{array}$ & $\begin{array}{c}\text { Moderately } \\
\text { true }\end{array}$ & $\begin{array}{c}\text { Mostly } \\
\text { true }\end{array}$ & Very much true \\
\hline
\end{tabular}

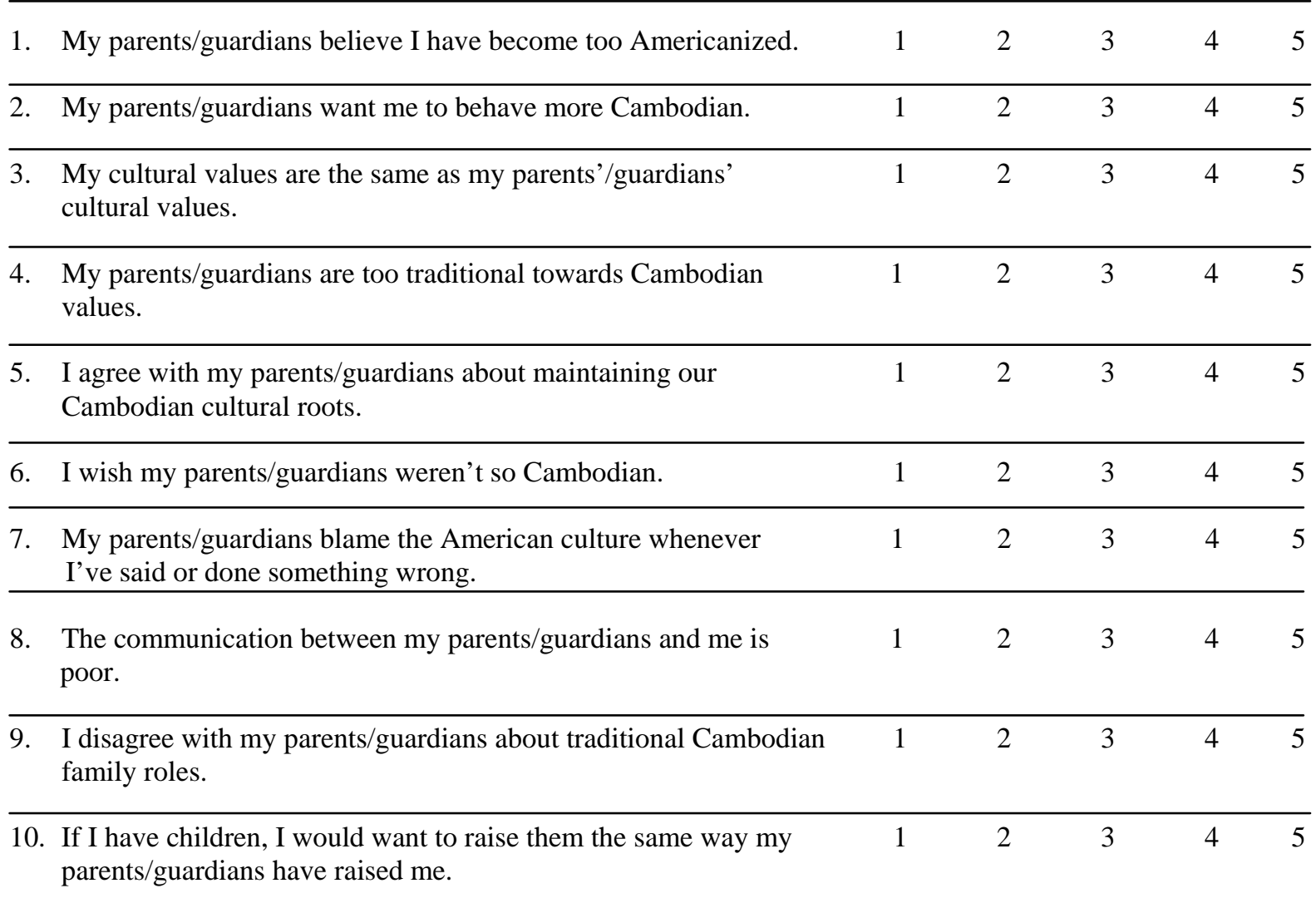




\section{References}

Aldwin, C., \& Greenberger, E. (1987). Cultural differences in predictors of depression. American Journal of Community Psychology, 15(6), 789-813.

Andrews, B., \& Wilding, J. M. (2004). The relation of depression and anxiety to life-stress and achievement in students. British Journal of Psychology, 95(4), 509-521.

Berry, J. W. (2003). Conceptual approaches to acculturation. In K. M. Chun, P. B. Organista, \& G. Marin (Eds.), Acculturation: Advances in theory, measurement, and applied research (pp. 17-37). Washington, DC: American Psychological Association.

Berry, J. W., Phinney, J. S., Sam, D. L., \& Vedder, P. (2006). Immigrant youth: Acculturation, identity, and adaptation. Applied Psychology (An International Review), 55(3), 303-323.

Buki, L. P., Ma, T. C., Strom, R. D., \& Strom, S. K. (2003). Chinese immigrant mothers of adolescents: Self-perceptions of acculturation effects on parenting. Cultural Diversity \& Ethnic Minority Psychology, 9(2), 127-140.

Carlson, E., \& Rosser-Hogan, R. (1993). Mental health status of Cambodian refugees ten years after leaving their homes. American Journal of Orthopsychiatry, 63(2), 223-231.

Chan, S. (2004). Survivors: Cambodian refugees in the United States. Chicago, IL: University of Illinois Press.

Chang, J. \& Le, T. (2005). The influence of parents, peer delinquency, and school attitudes on academic achievement in Chinese, Cambodian, Laotian or Mien, and Vietnamese youth. Crime \& Delinquency, 51(2), 238-264.

Chung, R. C. (2001). Psychosocial adjustment of Cambodian refugee women: Implications for mental health counseling [Electronic version]. Journal of Mental Health Counseling, 23(2), 115-126.

Chung, R. C., Bemak, F., \& Kagawa-Singer, M. (1998). Gender differences in psychological distress among Southeast Asian Refugees. The Journal of Nervous and Mental Disease, 186(2), 112-119.

Congress, E. P., \& Lynn, M. (1994). Group work programs in public schools: Ethical dilemmas and cultural diversity. Social Work in Education, 16(2), 107-114.

Dinh, K. T. (2005). Dinh intergenerational conflict inventory. Unpublished instrument.

Dinh, K. T., \& Nguyen, H. H. (2006). The effects of acculturative variables on Asian American parent-child relationships. Journal of Social and Personal Relationships, 23(3), 407-426.

Dinh, K. T., Sarason, B. R., \& Sarason, I. G. (1994). Parent-child relationships in Vietnamese immigrant families. Journal of Family Psychology, 30, 295-309.

Drachman, D. (1992). A stage-of-migration framework for service to immigrant populations. Social Work, 37(1), 68-72.

Earm, S. (2002). The acculturation of Cambodian family of different generations. Retrieved August 19, 2008 from St. Olaf College, Department of Sociology Web site: http://www.stolaf.edu/depts/sociology/major/373/373final_papers_2002/cambodian_fami ly.html

Feliciano, C., \& Rumbaut, R. G. (2005). Gendered paths: Educational and occupational expectations and outcomes among adult children of immigrants. Ethnic and Racial Studies, 28(6), 1087-1118.

Fuligni, A. J. (2001). Family obligation and the academic motivation of adolescents from Asian, Latin American, and European backgrounds. In A. J. Fuligni (Ed.), Family obligation 
and assistance during adolescence: Contextual variations and developmental implications (pp. 61-75). San Francisco, CA: Jossey-Bass.

Fuligni, A. J., \& Witkow, M. (2004). The postsecondary educational progress of youth from immigrant families. Journal of Research on Adolescence, 14, 159-183.

Goldberg, M. (1999). Truancy and dropout among Cambodian students: Results from a comprehensive high school. Social Work in Education, 21(1), 49-63.

Goodenow, C. (1993). The psychological sense of school membership among adolescents: Scale development and educational correlates. Psychology in the Schools, 30(1), 79-90.

Hagborg, W. J. (1998). An investigation of a brief measure of school membership. Adolescence, 33(130), 461-468.

Hammond, C. (2004). The impacts of learning on well-being, mental health and effective Coping. In T. Schuller, J. Preston, C. Hammond, A. Brassett-Grundy, \& J. Bynner (Eds.), The benefits of learning: The impact of education on health, family life, and social capital (pp. 57-79). New York: RoutledgeFalmer.

Hernandez, D. J. (1993). America's children: Resources from family, government, and the economy: A census monograph series. New York: Russell Sage Foundation.

Hsu, E., Davies, C. A., \& Hansen, D. J. (2004). Understanding mental health needs of Southeast Asian refugees: Historical, cultural, and contextual challenges. Clinical Psychology Review, 24, 193-213.

Kao, G., \& Tienda, M. ( 1995). Optimism and achievement: The educational performance of immigrant youth. Social Science Quarterly, 76(1), 1-19.

Keo, S. (2001). Child-rearing and discipline among Cambodian Americans. 2004 Khmer Institute, Thesis 001. Retrieved August 13, 2005 from http:/www.khmerinstitute .org/research/thesis1/t1c.html.

Kinzie, D. J., \& Sack,W. (2002). The psychiatric disorders among Cambodian adolescents: The effects of severe trauma. In F. J. Azima \& N. Grizenko (Eds.), Immigrant and refugee children and their families: Clinical, research, and training issues (pp. 95112). Madison, CT: International Universities Press.

LaFramboise, T., Coleman, H., \& Gerton, J. (1993). Psychological impact of biculturalism: Evidence and theory. Psychological Bulletin, 114(3), 395-412.

Laible, D. J., Carlo, G., \& Raffaelli, M. (2000). The differential relations of parent and peer attachment to adolescent adjustment. Journal of Youth and Adolescence, 29(1), 45-59.

Lambert, W. E., \& Taylor, D. M. (1990). Coping with cultural and racial diversity in urban America. New York: Praeger.

Larson, C. S., Gomby, D. S., Shiono, P. H., Lewit, E. M., \& Behrman, R. E. (1992). Schoollinked services: Analysis. The Future of Children, 2(1), 6-18.

Lotspeich, K., Fix, M., Perez-Lopez, D., \& Ost, J. (2003, October). A profile of the foreign-born in Lowell, Massachusetts. The Urban Institute. Retrieved August 13, 2005 from http://www.urban.org/url.cfm?ID=410918.

Marshall, G. N., Schell, T. L., Elliott, M. N., Berthold, M. S., \& Chun, C. A. (2005). Mental health of Cambodian refugees two decades after resettlement in the United States. Journal of the American Medical Association, 294(5), 571-579.

Massachusetts Department of Education (2004-2005). Lowell High Directory Information. Retrieved April 21, 2005 from http://profiles.doe.mass.edu/home.asp?mode=so\&so=936$6 \&$ ot $=5 \& 0=907 \&$ view $=$ all. 
Mok, M. M. C. (2006). Introduction to the special issue on affective and social outcomes of schooling [Special Issue]. Educational Psychology, 26(2).

Mollica, R. (1994). Southeast Asian refugees: Migration history and mental health issues. In A. J. Marsella \& T. Bornemann (Eds.), Amidst peril and pain: The mental health and wellbeing of the world's refugees (pp. 83-100). Washington, DC: American Psychological Association.

Mollica, R. F., Poole, C., Son, L., Murray, C. C., \& Tor, S. (1997). Effects of war trauma on Cambodian refugee adolescents' functional health and mental health status. Journal of the American Academy of Child and Adolescent Psychiatry, 36(8), 1098-1107.

Mortland, C. A. (1996). Khmer. In D. W. Haines (Ed.), Refugees in American in the1990's: A reference handbook (pp. 232-258). Westport, CT: Greenwood Press.

Niedzwiecki, M., \& Duong, T. C. (2004). Southeast Asian American statistical profile [Electronic version]. Washington, DC: Southeast Asia Resource Action Center (SEARAC). Retrieved April 1, 2006 from http://www.searac.org/seastatprofilemay 04.pdf.

Ngo, B., \& Lee, S. J. (2007). Complicating the image of model minority success: A review of Southeast Asian American education. Review of Educational Research, 77(4), 415-453.

Nguy, N. (2000). Obstacles to the educational success of Cambodians in America. 2004 Khmer Institute, Article 002. Retrieved July 23, 2005 from http://www.khmerinstitute.org.

Ong, A. (2003). Buddha is hiding: Refugees, citizenship, the new America. Berkeley, CA: University of California Press.

Orme, J. G., Reis, J., \& Herz, E. J. (1986). Factorial and discriminant validity of the Center for Epidemiological Studies Depression (CES-D) Scale. Journal of Clinical Psychology, 42(1), 28-33.

Oropesa, R. S., \& Landale, N. S. (1997). Immigrant legacies: Ethnicity, generation, and children's familial and economic lives. Social Science Quarterly, 78(2), 399-416.

Portes, A., \& MacLeod, D. (1999). Educating the second generation: Determinants of academic achievement among children of immigrants in the United States. Journal of Ethnic \& Migration Studies, 25(3), 373-397.

Portes, A., \& Rumbaut, R. G. (2001). Legacies: The story of the immigrant second generation. Berkeley, CA: University of California Press.

Radloff, L. S. (1977). The CES-D Scale: A self-report depression scale for research in the general population. Applied Psychological Measurement, 1(3), 385-401.

Redfield, R., Linton, R., \& Herskovits, M. (1936). Memorandum on the study of acculturation. American Anthropologist, 38, 149-152.

Rumbaut R. G., \& Ima, K. (1988). The adaptation of Southeast Asian refugee youth: A comparative study: Final report to the office of resettlement. Washington, DC: U.S. Office of Refugee Resettlement.

Salyer, K. M., \& Holmstrom, R. W. (1991). Learning disabilities as a childhood manifestation of severe psychopathology. American Journal of Orthopsychiatry, 61(2).

Sanchez, B., Colon, Y., \& Esparza, P. (2005). The role of sense of school belonging and gender in the academic adjustment of Latino adolescents. Journal of Youth and Adolescence, 34(6), 619-638.

Santisteban, D. A., \& Mitrani, V. B. (2003). The influences of acculturation processes on the family. In K. M. Chun, P. B. Organista, \& G. Marin (Eds.), Acculturation: Advances in 
theory, measurement, and applied research (pp. 121-135). Washington, DC: American Psychological Association.

Shahar, G., Henrich, C. C., Winokur, A., Blatt, S. J., Kuperminc, G. P., \& Leadbeater, B. J. (2006). Self-criticism and depressive symptomatology interact to predict middle school academic achievement. Journal of Clinical Psychology, 62(1), 147-155.

Sharp, B. (2003, October 15). The Banyan tree: Untangling Cambodian history. Cambodia: Beauty and darkness. Retrieved August 13, 2005 from http://www.mekong.net/ cambodia/banyan1.htm.

Shields, M. K., \& Behrman, E. (2004). Children of immigrant families: Analysis and recommendations. The Future of Children, 14(2), 4-15.

Silka, L., \& Tip, J. (1994). Empowering the silent ranks: The Southeast Asian experience. American Journal of Community Psychology, 22(4), 497-514.

Southeast Asian Archive. (1999). Documenting the Southeast Asian refugee experience. Retrieved November 26, 2004, from University of California, Southeast Asian Archive Web Site: http://www.lib.uci.edu/libraries/collections/sea/seaexhibit/index.html.

Suárez-Orozco, M. M. (1989). Central American refugees and U.S. high schools: A psychosocial study of motivation and achievement. Stanford, CA: Stanford University Press.

Tan, S. (2000). Juvenile crimes: Cambodian teens at risk. 2005 Khmer Institute, Article 001. Retrieved July 23, 2005 from http://www.khmerinstitute.org/articles/art01.html.

Tsai, J. L., Ying, Y. W., \& Lee, P. A. (2000). The meaning of "being Chinese" and "being American”: Variation among Chinese American young adults. Journal of Cross-Cultural Psychology, 31(3), 302-332.

Weinberg, W. A., McLean, A., Swider, R. L., Nickols, A. S., Rintelmann, J. W., Erwin, P. R., et al. (1989). Depression, learning disability and school behavior problems. Psychological Reports, 64(1), 275-283.

Wills, T. A., \& Cleary, S. D. (1997). The validity of self-reports of smoking: Analyses by race/ethnicity in a school sample of urban adolescents. American Journal of Public Health, 87(1), 56-61.

Wood, H. (2001, Fall). Julie Mallozzi’s “Monkey Dance”. Mass Humanities, 3-6. Retrieved August 13, 2005 from Massachusetts Foundation for the Humanities Web Site: http://www.mfh.org/newsandevents/newsletter/MassHumanities/Fall2001/monkey.html.

Wright, W. (1998). The education of Cambodian American students in the Long Beach Unified School District: A language and educational policy analysis. Retrieved December 4, 2004 from Web Site: http://www.public.csu.edu/ wwright/thesis.htm\#District $\% 20$ Policies.

Yang, K. (2004). Southeast Asian American children: Not the "model minority.” The Future of Children, 14(2), 127-133.

Yao, E. L. (1985). Adjustment needs of Asian immigrant children. Elementary School Guidance \& Counseling, 19(3), 222-227.

Ying, Y. W., \& Tracy, L. C. (2004). Psychometric properties of the intergenerational congruence in immigrant families_-Parent scale in Chinese Americans. Social Work Research, 28(1), 56-62.

Zhou, M. (1997). Growing up American: The challenge confronting immigrant children and children of immigrants. Annual Review of Sociology, 23(1), 63-95. 


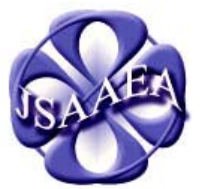

Volume 3

\section{Journal of Southeast Asian American Education \& Advancement} WWW.JSAAEA.org
A peer-reviewed scholarly journal published by the National Association for the Education \& Advancement of Cambodian, Laotian, and Vietnamese Americans (NAFEA)

\author{
Editor \\ Dr. Wayne E. Wright \\ University of Texas, San Antonio \\ Associate Editors \\ Dr. Chhany Sak-Humphry \\ University of Hawaii \\ Dr. KimOanh Nguyen-Lam \\ California State University, Long Beach \\ Book Review Editor \\ Dr. Leslie Turpin \\ School for International Training \\ Creative Works Editor \\ Phouang Hamilton \\ Washington Office of Superintendent of Public Instruction \\ Special Advisor \\ Anne Frank \\ University of California, Irvine, Southeast Asian Archives \\ Editorial Assistant \\ Mariana Kuhl \\ University of Texas, San Antonio
}

Comments and questions for the editorial staff may be directed to jsaaea@lists.sis.utsa.edu

\title{
Editorial Review Board
}

\author{
Dr. Carl L. Bankston III \\ Tulane University \\ Dr. Phala Chea \\ Lowell Public Schools \\ Dr. Changming Duan \\ University of Missouri, Kansas City \\ Dr. Nancy H. Hornberger \\ University of Pennsylvania \\ Dr. Peter Nien-Chu Kiang \\ University of Massachusetts, Boston
}

\author{
Dr. Pollie Bith-Melander \\ Asian and Pacific Islander Wellness Center \\ Dr. George Chigas \\ University of Massachusetts, Lowell \\ Dr. Sophal Ear \\ U.S. Naval Postgraduate School \\ Dr. Samlong Inthaly \\ Minneapolis Public Schools \\ Dr. Kevin K. Kumashiro \\ University of Illinois, Chicago
}


Dr. Stacey Lee

University of Wisconsin, Madison

Dr. Sue Needham

California State University, Dominguez Hills

Dr. Max Niedzwiecki

Daylight Consulting Group

Dr. Clara Park

California State University, Northridge

Dr. Loan T. Phan

University of New Hampshire

Dr. Karen Quintiliani

California State University, Long Beach

Dr. Fay Shin

California State University, Long Beach

Dr. Yer J. Thao

Portland State University

Dr. Khatharya Um

University of California, Berkeley

Dr. Terrence G. Wiley

Arizona State University
Dr. David Chanpannha Ley

Montgomery County Public Schools

Dr. Bic Ngo

University of Wisconsin-Madison

Dr. Leakhena Nou

California State University, Long Beach

Dr. Mark Pfeifer

Texas A\&M University, Corpus Christi

Dr. Bounlieng Phommasouvanh

Minnesota Department of Education

Dr. Kalyani Rai

University of Wisconsin, Milwaukee

Dr. Nancy J. Smith-Hefner

Boston University

Dr. Myluong Tran

San Diego State University

Dr. Linda Trinh Vo

University of California, Irvine

Dr. Zha Blong Xiong

University of Minnesota

Dr. Kou Yang

California State University, Stanislaus

\section{Doctoral Student Editorial Review Board}

\section{Keo Chea}

University of Pennsylvania

Loan Dao

University of California, Berkeley

Ha Lam

Arizona State University

Vanna Som

Harvard University

Giang Pham

University of Minnesota

Tinou Tran

University of Houston, Texas

Phitsamay Sychitkokhong Uy

Harvard University
Vichet Chhuon

University of California, Santa Barbara

Annie BichLoan Duong

San Joaquin County Office of Education

Ravy Lao

University of California, Santa Barbara

Rassamichanh Souryasack

University of California, Santa Barbara

Layheng Ting

State University of New York, Albany

Loan Tran

University of California, Santa Barbara

Yang Sao Xiong

University of California, Los Angeles 